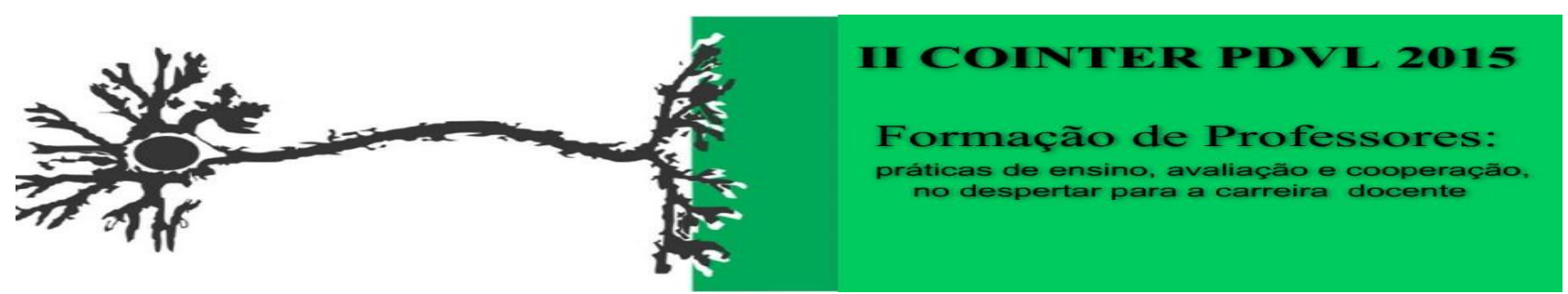

\title{
VISITAÇÃO TÉCNICA COM AULA DE CAMPO A UMA CACHAÇARIA PARA ABORDARGEM TEÓRICO-PRÁTICA DA PRODUÇÃO DA CACHAÇA
}

Apresentação: Relato de Experiência

Francisco das Chagas de Sousa ${ }^{1}$; Tetisuelma Leal Alves ${ }^{2}$; Jânio Eduardo de Araújo Alves ${ }^{3}$; Joabis Nobre Martins ${ }^{4}$.

\section{Introdução}

O ensino formal, mesmo a nível superior, é pautado na aprendizagem apenas a espaços limitados, que são as salas de aula, sem que haja interação do estudante com situações práticas. A educação em ciências deve privilegiar espaços não formais para a prática didático-pedagógica de modo a possibilitar ao estudante um processo de construção do conhecimento através da junção entre a teoria e prática (TEIXEIRA et al., 2012), assim a sala de aula fica responsável pelas teorias acadêmicas, enquanto os espaços fora da sala trazem o conhecimento prático. Em particular no ensino da química, percebe-se que os alunos, muitas vezes, não conseguem aprender, não são capazes de associar o conteúdo estudado com seu cotidiano, tornando-se desinteressados pelo tema, o que indica um ensino descontextualizado (NUNES e ADORNI, 2010). As visitas técnicas constituem um extraordinário instrumento de motivação para os estudantes, contribuindo na fixação de conteúdos e também como forma de dinamizar as aulas, pois, través delas o estudante pode conhecer ambientes diferentes da sala de aula (SILVA et al. 2011).

\section{Relato de Experiência}

Foi proposta para as disciplinas de Química Geral e Química Orgânica, de Tecnologia em Alimentos, visitação técnica com aula de campo ao Engenho São Pedro na cidade de Triunfo, PE. A metodologia foi de exposição dialogada, onde foi apresentado aos estudantes os processos de fabricação da cachaça. Simultaneamente ao diálogo explicativo, dúvidas que surgiam iam sendo esclarecidas. À medida que a turma passava pelos processos; moagem, fermentação, destilação, estocagem, envelhecimento, foram incentivados a formularem perguntas que associavam com o conteúdo teórico abordado em sala, haja vista a visita técnica não ser tratada como um simples passeio, mas sim ritual de formalidades didáticas e pedagógicas (VELOSO, 2010). O envolvimento dos estudantes foi significativo, a visitação prevista para 30 minutos, envolveu 2 h e 9 minutos. Após a aula as dúvidas e esclarecimentos foram organizados para compor material didático.

\footnotetext{
${ }^{1}$ Químico Industrial, IF Sertão PE, Campus Salgueiro, sousafrancisco@rocketmail.com

${ }^{2}$ Licenciada em Química, IF Sertão PE, Campus Salgueiro, tetisuelma@hotmail.com

${ }^{3}$ Técnico em Agroindústria, IF Sertão PE, Campus Salgueiro, Janio.alves@ifsertão-pe.edu.br

${ }^{4}$ Técnico em Alimentos, IF Sertão PE, Campus Salgueiro, martinsinta@gmail.com
} 
Imagem 1: Etapas do processamento da fabricação da cachaça (moagem, fermentação, moagem). Fonte: Própria.
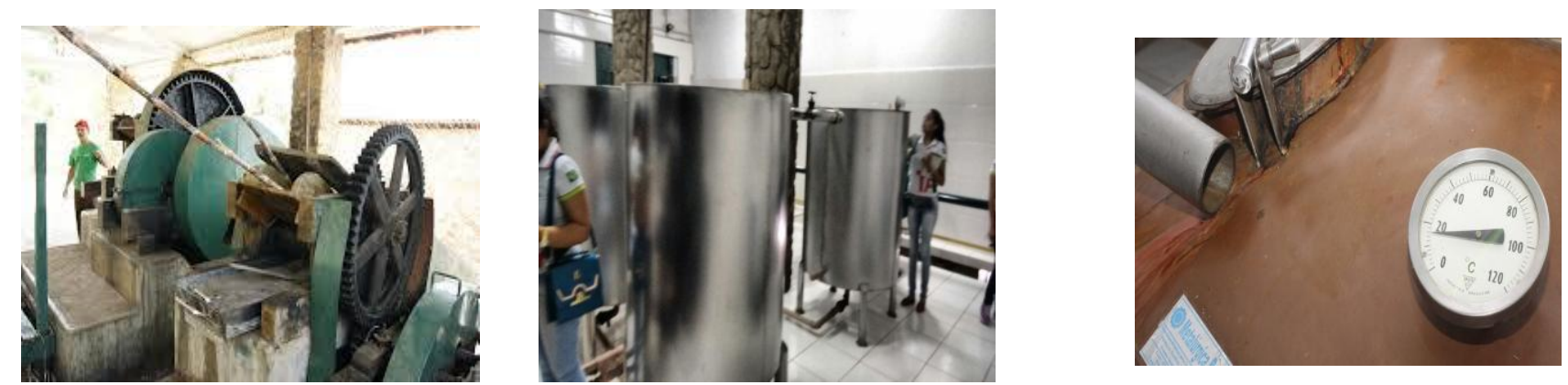

Imagem 2: Armazenamento, produtos comercializados, turma de Tecnologia em Alimentos. Fonte: Própria.
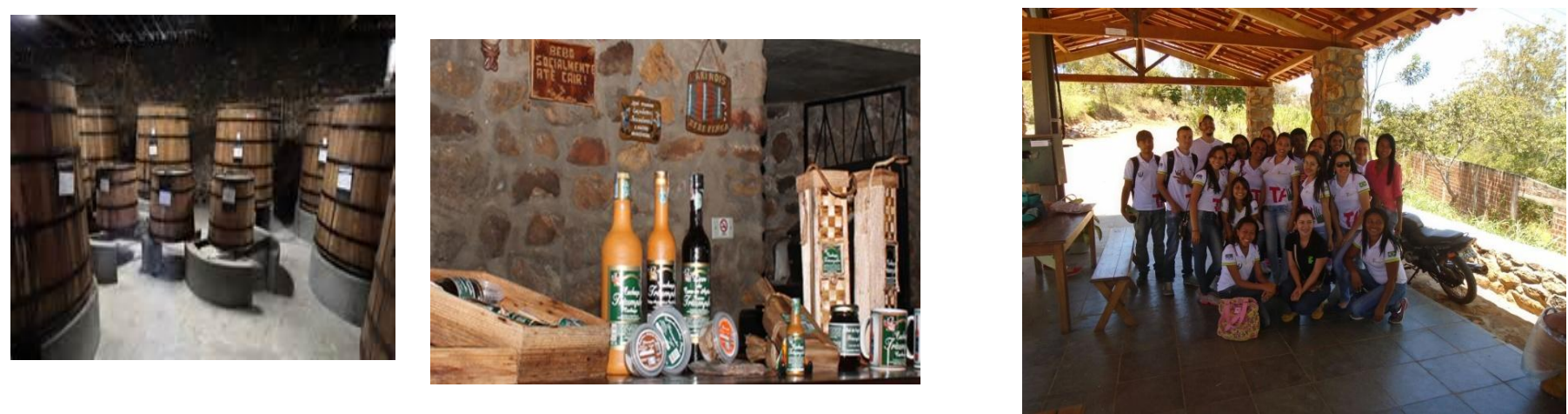

\section{Considerações}

Reitera-se aqui as vantagens de uma visitação técnica para contextualização teórica. Sendo não apenas explicativa e guiada, mas sim com uma proposta de discussão, debate e formação de material didático para reforçar o aprendizado. O conhecimento adquirido por essa experiência proporciona aos professores possibilidades de ampliar a prática descrita para novos moldes de ensino-aprendizagem que não se encaixe apenas a ambientes fechados e reclusos da vivência cotidiana.

\section{Referências}

NUNES, A. S.; ADORNI, D. S. O ensino de química nas escolas da rede pública de ensino fundamental e médio do município de Itapetinga - BA: o olhar dos alunos. In: Encontro Dialógico Transdisciplinar - Enditrans, Vitória da Conquista, BA, 2010.

SILVA, A. G. et al. Visitas técnicas no ensino da química - o tratamento das águas em destaque. In: 34ª Reunião Anual da Sociedade Brasileira de Química, Florianópolis, SC, 2011.

TEIXEIRA, H. B. et. al. A Inteligência naturalista e a educação em espaços não formais: um novo caminho para uma educação científica. Revista Amazônica de Ensino de Ciências, Manaus, v. 5, n. 9 , p. $55-66$, ago - dez, 2012.

VELOSO, M. P. Visita Técnica - uma investigação acadêmica (estudo e prática do turismo). Goiânia: Kelps, 2000. 